\title{
A MEDICALIZAÇÃO DE CRIANÇAS COM DIFICULDADES ESCOLARES DIAGNOSTICADAS COM TRANSTORNO DE DÉFICIT DE ATENÇÃO E HIPERATIVIDADE
}

\author{
Ederson Fernando Mariano ${ }^{1}$, Andréa Grano Marques ${ }^{2}$, Letícia Fleig Dal Forno ${ }^{3}$, \\ Tânia Maria Gomes da Silva ${ }^{4}$
}

1 - Psicólogo. Mestre em Promoção da Saúde do Programa de Mestrado em Promoção da Saúde do Centro Universitário Cesumar - UniCesumar - Maringá Paraná - Brasil.

2 - Professora Doutora do Programa de Mestrado em Promoção da Saúde do Centro Universitário Cesumar - UniCesumar - Maringá, Paraná. Pesquisadora, bolsista Produtividade em Pesquisa do Instituto Cesumar de Ciência, Tecnologia e Inovação - ICETI. - Maringá - Paraná - Brasil. andreagrano298@hotmail.com

3 - Professora Doutora do Programa de Mestrado em Gestão do Conhecimento do Centro Universitário de Maringá - UniCesumar - Maringá, Paraná. Pesquisadora, bolsista produtividade em Pesquisa do Instituto Cesumar de Ciência, Tecnologia e Inovação - ICETI - Maringá - Paraná - Brasil

4 - Professora Doutora do Programa de Mestrado em Promoção da Saúde do Centro

Universitário Cesumar - Unicesumar - Maringá, Paraná. Pesquisadora, Bolsista Produtividade em Pesquisa do Instituto Cesumar de Ciência, Tecnologia e Inovação - ICETI. - Maringá - Paraná - Brasil.

\section{Recebido em: 06/04/2019 - Aprovado em: 10/06/2019 - Publicado em: 30/06/2019 DOI: 10.18677/EnciBio_2019A153}

\section{RESUMO}

Objetivou-se neste artigo refletir sobre a medicalização de crianças com dificuldades escolares, diagnosticadas com Transtorno de Déficit de Atenção e Hiperatividade (TDAH). Trata-se de um estudo teórico realizado por meio de consulta em livros e artigos, nas seguintes bases de dados eletrônicas: Medline, LILACS e Scielo. Foram utilizadas na busca as seguintes palavras-chave: medicalização, dificuldade de aprendizagem, TDAH e ritalina. Verificou-se que as primeiras descrições médicas sobre este transtorno surgiram na primeira metade do século XX. À partir daí, diferentes nomenclaturas e conceituações foram utilizadas pelos pesquisadores. $\mathrm{Na}$ atualidade é grande o número de crianças diagnosticadas com TDAH. Suas principais características são a desatenção e hiperatividade-impulsividade. Crianças com TDAH são consideradas aquelas que mais têm problemas na escola. Não há consenso entre os pesquisadores sobre o TDAH ser uma pertubação de caráter biológico ou social. Tem havido por parte de muitos profissionais da educação uma validação do transtorno, com orientação às famílias para que procurem ajuda clínica para a solução das dificuldades escolares e comportamentais das crianças. Percebeu-se, assim, que a medicalização vem se sobrepondo a outras possibilidades menos invasivas de cuidados. Nesse sentido, este artigo propõe a ampliação de discussões que colaborem para a promoção da saúde infantil de forma mais humanística.

PALAVRAS-CHAVE: Medicalização, saúde, Transtorno de déficit de atenção e hiperatividade. 


\title{
REFLECTIONS ON MEDICALIZATION OF CHILDREN WITH SCHOOL DIFFICULTIES DIAGNOSED WITH DISORDER OF ATTENTION AND HYPERACTIVITY DEFICIT
}

\begin{abstract}
The objective of this article was to reflect on the medicalization of children with school difficulties diagnosed with Attention Deficit Hyperactivity Disorder (ADHD). This is a theoretical study carried out by consulting books, dissertations, theses and the following electronic databases: Medline, LILACS and SciELO. The following keywords were used in the search: medicalization, learning disability, ADHD and ritalin. It was found that the earliest medical descriptions of this disorder emerged in the first half of the twentieth century. From there, different nomenclatures and conceptualizations were used by the researchers. At present the number of children diagnosed with ADHD is great. Its main characteristics are inattention and hyperactivity-impulsivity. Children with ADHD are considered those who have the most problems in school. There is no consensus among researchers about ADHD to be a biological or social disturbance. There have been many validation of the disorder on the part of many educational practitioners, with guidance for families seeking clinical help to address children's school and behavioral difficulties. It has been realized, therefore, that medicalization has been superimposed on other less invasive possibilities of care. In this sense, this article proposes the expansion of discussions that collaborate to promote child health in a more humanistic way.

KEYWORDS: Attention deficit hyperactivity disorder, health, medication.
\end{abstract}

\section{INTRODUÇÃO}

Nos últimos anos tem havido crescente interesse por parte dos pesquisadores em compreender a dificuldade de algumas crianças no processo de aprendizagem escolar (AZEVEDO, 2018; SANTOS, FREITAS, 2018; SIGNOR et al., 2017; WAGNER et al., 2016). Parte considerável desses estudos tem computado a responsabilidade por essa dificuldade ao TDAH, sigla do Transtorno de Déficit de Atenção e Hiperatividade (RODRIGUES; CHECHIAM, 2017).

O Manual de Diagnóstico e Estatística dos Transtornos Mentais (DSM-V) define - TDAH como um transtorno neurobiológico, de causas genéticas, que aparece na infância e, quase sempre, acompanha o indivíduo por toda a vida. Para Lavagnino et al. (2018), os mecanismos neurobiológicos são considerados complexos e não dependem exclusivamente de um neurotransmissor, o que faz com que o transtorno se apresente com grande diversidade clínica.

Para Wagner et al. (2016), o Transtorno de Déficit de Atenção e Hiperatividade é definido como um transtorno neurodesenvolvimental caracterizado pela dificuldade de concentração, hiperatividade e impulsividade num nível mais grave do que o que tipicamente se observa em indivíduos em nível equivalente de desenvolvimento.

Conforme apontam Silva et al., (2012), crianças diagnosticadas com o transtorno têm sido tratadas com psicofármacos, notadamente a Ritalina, que é o estimulante mais consumido no mundo (SIGNOR et al., 2017). Trata-se de um psicotrópico de curta duração que pode ser usado associado a outros medicamentos, apresentando efeitos colaterais visíveis e que tem sido alvo de muitas críticas por parte dos profissionais da medicina que se opõem à medicalização (LEONARDO; SUZUKI, 2016).

No mundo contemporäneo, a medicalização da vida aparece como uma discussão mais marcante da cultura ocidental. A partir de Barroco et al. (2017), 
entende-se por medicalização o processo pelo qual questões de ordem social, política e econômica passam a ser de ordem médica, pensadas como doenças ou transtornos que exigem medicamentos, assegurando obediência às normas sociais.

A prevalência mundial do Transtorno de déficit de atenção e hiperatividade é alta. Para Wagner et al. (2016), os sintomas têm início na infância e persistem na adolescência e na vida adulta em um número considerável de casos.

Segundo a neuropsiquiatra llina Singh, em entrevista concedida a Santos e Freitas (2016), poucos tópicos geram um debate tão acalorado quanto o uso de drogas estimulantes do aprimoramento cognitivo das crianças. Ela alerta que enquanto os debates acontecem, o uso de medicamentos cresce acima de $20 \%$ ao ano, com variáveis de um país para outro. A prevalência diagnóstica em algumas áreas chega a $27 \%$ das crianças em idade escolar e uma estimativa mais sóbria do TDAH em crianças, embora também controversa, é de 5\% (SANTOS; FREITAS, 2016).

Recentemente, Singh afirmou que ainda existem muitas questões controversas relacionadas ao Transtorno de déficit de atenção e hiperatividade, notadamente quanto ao número de diagnósticos (SANTOS; FREITAS, 2018).

As preocupações sociológicas sobre o TDAH incorporam poucos aspectos analíticos relacionados à classe social, considerado um fator extremamente importante na investigação, segundo Singh. Falando sobre a situação do Reino Unido, a neuropsiquiatra informa que muitas escolas não estão equipadas/preparadas para lidar com qualquer tipo de problema mental com crianças e que, provavelmente, algumas dessas crianças serão identificadas como portadoras de transtorno unicamente por serem pobres ou pertencerem a minorias étnicas (SANTOS; FREITAS, 2018).

No Reino Unido é comum que a indústria farmacêutica convide professores para suas conferências e prepare material para que eles possam entender o Transtorno de Déficit de Atenção e Hiperatividade. Ilina, de acordo com Santos e Freitas (2018) vê tal situação como podendo ser benéfica, em certo sentido, no caso do professor/a ajudar um aluno que efetivamente precise, mas lamenta não haver um trabalho empírico para investigar se depois que os professores terminam o treinamento de dois dias ocorre um aumento no número de diagnósticos na escola.

Nesse aspecto, conclui-se que há necessidade de uma estratégia melhor para os serviços de saúde mental nas escolas, de modo a educar os profissionais sobre e saúde mental sobre as necessidades dos alunos, garantindo que os que precisarem de ajuda a recebam. Além disso, sugere-se que se avalie cuidadosamente o que acontece quando os professores têm esse conhecimento e se, à partir daí, eles filtram as suas observações através da lente do diagnóstico. Por fim, afirma-se que é preciso entender até que ponto o diagnóstico de TDAH está beneficiando ou não as crianças. Não há este tipo de pesquisa e llina Singh é cética quanto à viabilidade de que venha a ter, porque considera que este é um tipo de estudo que tem pouco financiamento (SANTOS; FREITAS, 2018).

$\mathrm{Na}$ direção de questionar a eficácia dos estimulantes no tratamento de TDAH, estudos como os de Silva et al., (2012) têm buscado essa resposta. Aproximadamente $25 \%$ das crianças observadas não apresentam resposta à medicação. Para os autores, entre as que apresentaram melhora na motivação, coordenação motora, habilidade visomotora e aprendizagem em curso prazo não há, de todo modo, garantias de que tal efeito tenha se dado em função do medicamento, devendo-se considerar antes a melhora no desempenho nacional da educação. 
Segundo Caliman (2010), a história do TDAH tem sido sempre permeada pela busca de legitimação de um discurso, o neurobiológico, e apesar de ser um dos transtornos mais estudados no campo da neuropsiquiatria, mantêm-se ainda permeado por controvérsias e incertezas. O diagnóstico inicial se deu no século XX, com alterações conceituais e de critérios de identificação ao longo dos anos. A terminologia variou, passando de encefalite letárgica, lesão cerebral mínima, hipercinesia, doença de déficit de atenção até chegar, finalmente, a transtorno de déficit de atenção/hiperatividade. Houve também alteração no quadro diagnóstico que, a partir da década de 1970, deixou de estar centrado na hiperatividade e se deslocou para o sintoma de desatenção. Desde então, passou-se a considerar que o transtorno podia ocorrer mesmo quando não houvesse a presença do elemento hiperativo. Na década de 90, ainda de acordo com Caliman (2010), o transtorno recebeu nova interpretação, passando a ser tido como um defeito inibitório que estava na base do desenvolvimento do quadro psicopatológico.

Não há um discurso científico definido sobre o TDAH. Algumas pesquisas defendem aspectos orgânicos do transtorno, conforme estabelece o Manual Estatístico dos Transtornos Mentais (DSM-V). Seguindo essa perspectiva, Wagner, Rohde e Trentini (2016) e Castro e Lima (2018), defendem que o TDAH seria o resultado de um transtorno no cérebro ou em seu funcionamento, tendo origem genética. Traumas na parte frontal do cérebro ou doenças cerebrais também poderiam deixar as crianças mais propensas a desenvolver os sintomas.

Rohde e Matos (2003), Moreti et al. (2011) e Toassa (2012), trazem uma outra linha interpretativa. Essa caminha no sentido de defender que os comportamentos identificadores do TDAH são resultantes das experiências sociais das crianças. Nesse aspecto, haveria uma frequente exposição dessas crianças diagnosticadas com o transtorno a tratamentos desnecessários (TOASSA, 2012).

As crianças se encontram inseridas numa sociedade contemporânea cada vez mais "aflita", inquieta e com dificuldades existenciais profundas, e, por isso, os comportamentos infantis seriam apenas um reflexo do real (BAUMAN, 2009).

Uma crítica frequente aos argumentos pró-medicamentos, apontado por Santos e Freitas (2016), tem sido a de que estes estão sendo utilizados para o "tratamento" de comportamentos indesejáveis das crianças como parte de uma biopolítica opressiva. Das crianças se esperaria um tipo de comportamento idealizado e aquelas que a ele não se adequam seriam justamente as que seriam patologizadas.

Essas duas lógicas de abordagem do TDAH, a biomédica e a psicossocial, encontram defensores ardorosos por parte de profissionais das áreas de educação, da saúde e também da família. O que parece ser um ponto em comum aos estudos é que as crianças definidas como "hiperativas" têm sido sempre consideradas como aquelas que apresentam maior dificuldade na escola, segundo estudos de Silva (2016) e Tada, (2017).

Larroca e Domingos (2012) estão entre aqueles que acreditam que os sintomas que definem o TDAH, como a desatenção, a impulsividade e a hiperatividade não constituem uma descrição médica clara e unificada, sendo antes traços inerentes à natureza humana. Nesse aspecto, entendem que comportamentos próprios ao humano, notadamente ao universo infantil, estão sendo patologizados, num tipo de julgamento que extrapola o campo científico para inserir-se em questões sociais e morais. Quanto à descrição de comportamento desatento, as autoras são ainda mais reticentes, afirmando que as manifestações clínicas que conduzem a esse diagnóstico podem ter como causa múltiplos fatores: déficits sensoriais e intelectuais, distúrbios do sistema reticular, danos cerebrais 
frontais e límbicas, danos cerebrais perinatais no lobo frontal, hábitos de sono, além de elementos externos e psicossociais, como uma situação familiar caótica ou um sistema de ensino inadequado (LARROCA; DOMINGOS, 2012).

$O$ século $X X$ foi o momento de consolidação definitiva do poder/saber da medicina. Desde os séculos XVIII-XIX teve início a instauração de um poder médico disciplinar que, sob a licença do Estado, teve como propósito o controle sobre os corpos dos indivíduos. Homens, mulheres e crianças, especialmente os procedentes das camadas populares, foram instados a se enquadrar dentro de um modelo comportamental adequado aos interesses do Estado. Qualquer desvio do padrão era entendido como patologia. A essa prática de interferência na vida e nos corpos dos indivíduos, Foucault (2016) denominou biopoder.

$O$ advento da puericultura marcou a interferência dos médicos nas dinâmicas das famílias pobres. A escola foi um espaço legitimador desse poder sobre as famílias. Para Decotelli et al. (2013), os educadores aliaram-se aos médicos especialmente na busca do entendimento da não aprendizagem infantil que, desde então, vem sendo associada a fatores orgânicos

O presente estudo, de caráter teórico, tomou como fonte de consulta livros e artigos científicos selecionados por meio de bases de dados eletrônicos, notadamente Medline, LILACS e Scielo. Objetiva refletir sobre a medicalização de crianças com dificuldades de aprendizagem, normalmente diagnosticadas como portadoras de Transtorno de Déficit de Atenção e hiperatividade, tratadas com metilfenidatos, notadamente a ritalina.

\section{A DIFICULDADE NA APRENDIZAGEM E O DIANÓSTICO DE TDAH}

Compreender o processo que envolve a aprendizagem de uma criança é uma tarefa que tem seduzido inúmeros pesquisadores, sendo Vigotsky e Piaget, de acordo com Giusta (2013), as duas referências mais importantes. Ambos pensavam a criança como um ser em constante atividade cerebral e de aprendizagem, mas enquanto a epistemologia genética piagetiana concebe o desenvolvimento cognitivo como resultante de estruturação e reestruturação da ação e valida a gênese das operações do pensamento na inteligência sensório-motora, Vigotsky segue em outra linha de entendimento (GIUSTA, 2013).

Também Leonardo e Suzuki (2016) farão referência às diferentes formas de entendimento acerca do processo de aprendizagem que é trazido por diferentes autores.

\footnotetext{
Para Vigotski, os fatores biológicos são preponderantes no início da vida da criança e são responsáveis pelas funções psicológicas elementares - reações automáticas e ações reflexas. Leontiev complementa expondo que as funções psicológicas superiores, que são especificamente humanas, formam-se nas relações sociais entre os homens, no processo de produção da vida, por meio da apropriação da cultura humana transmitida de geração a geração (LEONARDO; SUZUKI, 2016, p.48).
}

Conforme Toassa (2012), Tada et al., (2017), Boccato et al. (2017), há muitas complexidades que acompanham o processo de aprender, e a superficialidade de diagnósticos das crianças que não apresentam um desempenho satisfatório no sistema educacional é um dado preocupante.

A dificuldade de uma criança em aprender é algo que a penaliza, assim como a toda família que cria expectativas de que a determinada faixa etária corresponda um 
saber específico. Para Suzuki et al. (2017), a criança que não aprende no tempo e no modo esperado é rotulada e encaminhada para o médico. A consequência disso é um número cada vez maior de crianças medicalizadas, deslocando o eixo de análise da sociedade para o organismo do indivíduo.

Crianças apresentando dificuldades escolares é um velho problema na educação. O que é novidade e vem ocorrendo num crescente, como apontam Santos e Freitas (2018), é que as antigas soluções, como as aulas de reforço fora da escola, estão sendo substituídas pelas drogas psicotrópicas.

O processo de aprendizagem é complexo, frágil e permeado pelas muitas particularidades tanto do sujeito que aprende quanto daquele que ensina. Segundo Perrenoud (2001), para aprender é preciso que o indivíduo dê sentido ao que aprende, sinta-se reconhecido, compreendido e apoiado, tenha confiança e esteja ciente de que pode contar com a confiança dos outros, que o consideram capaz de conseguir alcançar seus objetivos.

Micaroni et al., (2010) reforçam que uma causa da dificuldade de aprendizagem da criança no âmbito escolar pode estar no arraigado conceito da relação ensino-aprendizagem que, no Brasil, se baseia na relação professor que fala/ensina versus alunos que ouvem/aprendem, com a atenção focalizada tida como condição fundamental para a aprendizagem.

Para Perrenoud (2001), nos anos 60 do século passado surgiu a preocupação com o fracasso escolar e muitas medidas governamentais foram tomadas em diferentes países buscando dar uma solução aos problemas, mas nunca foi elaborada uma teoria correta sobre o que efetivamente acontece. Para o autor, há uma grande complexidade dos processos mentais e sociais envolvendo esta discussão, além de flutuações políticas, renovação dos currículos, rupturas teóricas e ideológicas. No passado, o fato de uma criança não ir bem na escola, a depender da classe social da criança, não era algo incomum ou tampouco preocupante.

O fracasso escolar é uma ideia moderna, que data de meados do século XX (....). Isso não significa que todas as crianças aprendiam na escola, mas que fazia parte da ordem das coisas que, no seio de uma geração, somente uma minoria tivesse pleno acesso à cultura. (...) O fracasso escolar maciço, ao menos na escola elementar, só surgiu como fenômeno de massa quando todas as crianças foram reunidas e comparadas em um exame de ingresso no ensino secundário (PERRENOUD, 2001, p.16).

Seguindo ainda na observação de Perrenoud (2001), citada acima, observa-se que o fracasso escolar só era tido como um problema quando envolvendo crianças de origem social elevada. Fora isso, a alfabetização mínima era suficiente. Perrenoud (2001) propõe, assim, uma investigação de cada sistema escolar em específico para se compreender quando efetivamente o fracasso escolar das camadas populares passou a ser entendido como um problema.

De acordo com Rodrigues e Chechia (2017), o fracasso escolar sempre existiu no Brasil, mas foi estabelecido em fins do século XIX com a instauração da escolaridade obrigatória, dentro de uma perspectiva de atendimento às necessidades produtivas da sociedade capitalista.

Do ponto de vista da organização e da gestão, a educação no Brasil vem apresentando mudanças importantes, a partir de alterações introduzidas pela Constituição de 1988, e da Lei de Diretrizes e Bases da Educação Nacional (Lei 9393/96) e da aprovação do Plano Nacional de Educação, em 2001. Essas leis 
tiveram como propósito a organização, a gestão e as ações e políticas para garantir o acesso, a permanência e também a qualidade da educação, buscando cumprir os compromissos assumidos pelo Brasil no Fórum Mundial da Educação, em 2000, que preconizou garantia de educação para todos (BRASIL, 2005).

Contudo, o sistema educacional brasileiro tem sido vítima de muitas críticas por apresentar deficiências significativas (OLIVEIRA, 2015). Avaliar uma criança como sendo portadora de TDAH é uma tarefa que exige muita cautela. A avaliação deve ser feita por uma equipe multidisciplinar, com a opção pelo uso de medicamento sempre sendo do médico. Este deve ter como apoio a aplicação de testes psicométricos e exames de neuroimagens capazes de identificar alterações cerebrais, mas nem sempre é o que ocorre, afirmam Wagner, Rohde e Trenntini (2016). De acordo com os autores, a maneira como tem sido feito o diagnóstico do TDAH tem gerado controvérsias. As críticas caminham no sentido de entender que 0 perfil neuropsicológico dos pacientes é muito heterogêneo e os testes neuropsicológicos não sendo considerados suficientemente sensíveis e específicos para a construção do diagnóstico.

A subjetividade dos exames termina por torná-los insuficientes. Há ainda, de acordo com Wagner et al. (2016) casos em que o diagnóstico é feito a partir de ensaios terapêuticos em que o profissional avalia a criança a partir dos sintomas aparentes para prescrever a medicação. Outro dado agravante mencionado por Cruz et al. (2016), é que alguns profissionais da educação têm "diagnosticado" crianças com TDAH e até mesmo "indicado" o medicamento que a criança precisa tomar.

A escola é considerada pelas familias, notadamente as de menor poder econômico e cultural, como um espaço detentor/produtor de verdades. Quando uma professora, um diretor, uma coordenadora diz para uma mãe ou um pai que seu filho ou filha apresenta dificuldade de aprender e precisa procurar um profissional da medicina para receber medicação, estas são colocadas, quase sempre, numa situação de aceitação e angústia, sem grandes possibilidades de questionamento desse discurso legitimador (CRUZ et al., 2016)

O caminho seguido pelas famílias dessas crianças tem sido geralmente o de primeiro procurar um profissional da psicologia ou da psicopedagogia antes de buscar ajuda com o neurologista. Este último, geralmente, solicita um eletroencefalograma, o que demonstra uma associação do TDAH a aspectos cerebrais e orgânicos. O passo seguinte é a prescrição de medicamentos. Desse modo, os psicofármacos ganham cada vez mais espaço, pela facilidade e rapidez com que "resolvem" os problemas (FERNANDES; MARCONDES, 2017). Percebe-se nesse caso, que há um entrecruzamento de discursos de poder se impondo sobre as famílias. Primeiro o da escola, depois o dos médicos. Trata-se de saberes produzidos para enquadrar os "anormais" e os "desajustados" (FOUCAULT, 2015).

Nesse recorte, percebe-se que o avanço nas pesquisas empíricas tem levado ao reconhecimento de que múltiplas redes neurais estão envolvidas no transtorno e que alguns déficits estudados não podem ser encontrados em todos os indivíduos que recebem o diangóstico de TDAH. Para Wagner et al. (2016), as observações clínicas do comportamento das crianças que recebem o diagnóstico, associados aos relatos de pais e professores, não estão necessariamente correlacionados com os resultados de testes obtidos em ambientes de controle de avaliação, o que dificulta a generalização para a realidade. 
Rhode et al., (2000), afirmam que o diagnóstico do TDAH é feito baseado em análise comportamental da criança, enquadrada dentro do grupo de desatentos ou hiperativos, que, segundo a literatura especializada, tendem, entre outras atitudes a:

a) cometer erro por descuido;

b) apresentar dificuldade de se concentrar em tarefas e jogos;

c) ser desorganizado com os materiais e tarefas;

d) evitar esforço mental;

e) ter o hábito de perder coisas importantes.

Já o grupo dos hiperativos (impulsividade) apresenta:

a) movimento exagerado de pés e mãos;

b) sensação de inquietude;

c) fala demais;

d) não suporta aguardar a vez para qualquer atividade em grupo;

e) é barulhento e agitado.

De acordo com Rhode et al. (2000), sintomas isolados não são indicativos do transtorno, podendo acontecer em crianças "normais" uma vez ou outra, sendo preciso que haja um conjunto de sintomas frequentemente apresentado ao longo do tempo para comprovar o transtorno. Para Jerusalinsky (2011), os critérios oficiais para o TDAH consistem em comportamentos que podem tanto ser produto do tédio, da frustração quanto da falta de disciplina. $O$ autor alerta, inclusive, para a existência de estudos que afirmam não haver comprovação de base biológica para a existência do transtorno.

O que se tem como certo, é a associação mórbida entre a medicina e a indústria farmacêutica; fenômeno já denunciado por Illich. Este notou que, na década de 1970, o consumo de substâncias prescritas pelos médicos crescia mais velozmente do que o de bebidas alcoólicas (ILLICH, 1975). De lá para cá, a medicalização da vida vem se tornando um fenômeno cada vez mais recorrente, abarcando indivíduos de todas as idades, e a indústria farmacêutica tem sido cada vez mais vítima de críticas, acusada, inclusive de camuflar resultados de ensaiosclínicos, promover testagem inadequada de medicamentos novos e ter os fins lucrativos como elemento norteador de suas práticas (GOTZSCHE, 2016).

Deve-se considerar que a escola é um lugar instituído de ordem pública, dispositivo de inclusão/exclusão do sujeito na sociedade contemporânea (KAMERS, 2016).

Desse modo, Oliveira (2015) alerta que é imperativo que toda análise sobre as dificuldades de uma criança em aprender leve em consideração que políticas e programas educacionais pouco adequados às crianças da geração atual, professores sem preparo, a baixa qualidade do ensino formal e uma gestão engessada são dificuldades inerentes ao Sistema educacional do Brasil.

\section{RITALINA: MEDICANDO A INFÂNCIA}

A medicalizacão pode ser entendida como uma tendência da contemporaneidade de tratar por meio de medicamentos as mais diversas experiências humanas, na busca infrutífera por uma normatização da vida (MOYSÉS; COLLARES, 2013). O conceito de medicalização se consagrou a partir de investigações da década de 1970, tendo como referências as correntes marxistas 
e liberais humanistas (CARVALHO et al., 2015) e entendida como uma tendëncia da contemporaneidade de tratar por meio de medicamentos as mais diversas experiëncias humanas, na busca pela normatização da vida (LEONARDO; SUZUKI, 2016).

Entre os medicamentos mais prescritos para o TDAH está a Ritalina, conhecida como a "pílula da obediência". A Ritalina foi sintetizada na década de 1940 pelo químico litaliano Lendro Panizzon, mas inicialmente sem prescrição para crianças. Trata-se de um metilfenidato da família das anfetaminas, que teria o objetivo de melhorar a concentração, diminuir o cansaço e auxiliar no aprendizado. De acordo com apontamentos de Suzuki et al., (2017), o Brasil é o segundo maior consumidor mundial do medicamento. Barroco et al. (2017) mostram que em 2011, foram vendidas 1.212.850 caixas nas farmácias brasileiras, com um gasto estimado de $R \$$ 28,5 milhões das famílias. Segundo Decotelli et al. (2013) para que se justifiquem esses números é preciso que se criem patologias que denominem os desvios e as diferenças, fabricando subjetividades medicalizadas.

$\mathrm{O}$ aumento de crianças diagnosticadas com TDAH garante a sustentação do mercado farmacêutico (MACHADO; FERREIRA, 2014). Embora o déficit de atenção e a hiperatividade sejam os mais conhecidos, há outros, como, por exemplo, o transtorno desafiante opositor, transtorno bipolar, transtorno de ansiedade e dislexia que comprometeriam as funções cerebrais relacionados à linguagem, cognição e/ou a aprendizagem (SIGNOR et al., 2017).

Mesmo os estudos nacionais e internacionais que validam a existência do TDAH são críticos quanto ao número excessivo dos diagnósticos e ao uso de psicofármacos. Não há unanimidade entre os estudiosos sobre a Ritalina e sua contraindicação. Como o mecanismo de ação do metilfenidato é semelhante ao da cocaína, que aumenta a dopamina no cérebro, gera sensação de prazer e dessensibiliza o cérebro, os críticos do medicamento afirmam que o usuário passaria a depender continuamente da droga para as situações cotidianas da vida. Crianças tratadas com o medicamento apresentariam maior predisposição para se tornar consumidores de drogas na vida adulta. Moysés e Collares (2013) apontam que outras reações perigosas afetariam os usuários, como o comprometimento de todos os aparelhos e sistemas do corpo humano, especialmente o sistema nervoso central, o cardiovascular e o endócrino-metabólico.

No final do século passado, em A expropriação da saúde: Nêmesis da Medicina, Illich (1975) alertou para a crescente dependência da população ao uso de drogras presccritas pelos médicos, fenômeno que denominou de iatrogênese social e que pode ser traduzida por medicalização. Para esse autor, as angústias e as doenças provocadas pelos cuidados médicos constituiam-se na verdade, numa epidemia mais importante do que qualquer outra, embora não fosse reconhecida.

Atualmente é a vez de Gotzche (2016) fazer suas críticas à medicalização e denunciar a relação de interesses envolvendo médicos, indústrias farmacêuticas e editores de jornais científicos, responsabilizando-os por mentiras e camuflagens nas pesquisas que evidenciavam os malefícios de alguns medicamentos que podem ter levado crianças e adolescentes norte-americanos a cometerem suicídio. Cita como exemplo o Estudo 329 da Glaxo, multinacional farmacêutica sediada no Reino Unido e uma das maiores companhias do ramo no mundo.

Em 2001, a GlaxoSmithKline publicou um ensaio com crianças e adolescentes a que deu o nome de estudo 329. O estudo relatou que o antidepressivo Paxil (Seroxat), cloridrato de paroxetina, era eficaz e apresentava efeitos colaterais mínimos, sendo considerado digno de credibilidade. Em 2004, o procurador-geral do 
estado de Nova York processou a empresa por fraude repetida e persistente do consumidor com relação a ocultação de dados importantes acerca desse medicamento. Como parte de um acordo a empresa abriu seus arquivos e descobriu-se que a Glaxo mentia.

A Glaxo mentiu para sua equipe de vendas, dizendo que o ensaio 329 mostrava "Eficácia e segurança NOTÁVEIS", embora a empresa admitisse em documentos internos que o estudo não demonstrou que o Paxil era eficaz. O estudo era negativo para eficácia em todos os oito desfechos especificados por protocolo e positivo para dano. Esses fatos indiscutíveis foram eliminados com extensas manipulações de dados, de modo que o artigo publicado - embora tivesse sido redigito por escritor-fantasma, tinha 22 autores terminasse relatando efeitos positivos (GOTZSCHE, 2016, p. 209).

O estudo mostrou ainda que, em relação aos danos, ocorreram manipulações piores. O relatório interno do estudo inédito deixou evidenciado que, pelo menos oito crianças haviam cometido suicídio tomando Paxil, versus uma com placebo. Houve 11 efeitos adversos no total de 93 crianças tratadas com Paxil e duas entre 87 crianças tratadas com placebo, o que também era estatisticamente significativo. Os dados evidenciaram que, para 10 crianças tratadas com Paxil em vez de placebo, houve um evento adverso grave a mais. Entretanto, o resumo do artigo científico apresentado terminava concluindo que: "Em geral, a paroxetina é bem tolerada e eficaz para depressão maior em adolescentes" (GOTZSCHE, 2016, p. 209). Pelo menos três adolescentes ameaçaram ou tentaram suicídio, mas isso não foi descrito no artigo. Ainda segundo o autor mencionado, outras irregularidades foram observadas no estudo, embora o pesquisador principal, Dr. Martin Keller, nunca tenha admitido que a maneira como relatou o caso estava errada. Seu departamento recebeu 50 milhões de dólares em financiamento de pesquisa e suas viagens sempre foram reembolsadas tanto por sua universidade quanto pelo patrocinador farmacêutico.

\section{CONSIDERAÇÕES FINAIS}

Observou-se não haver um diagnóstico consensual sobre 0 TDAH, considerando-se que lhe são atribuídas muitas caracteríticas tidas como de caráter biológico que podem ser entendidas na perspectiva cutural e histórica, levando-se em consideração que as crianças se constróem em relação com o social.

Ao atribuir as dificuldades escolares de uma criança às características orgânicas e cerebrais, termina-se ocultando muitos outros condicionantes importantes, a exemplo da própria deficiência dos sistemas educacionais, tais como: currículos ultrapassados, professores despreparados, gestão deficiente, entre outros, deixando a cargo da família e das próprias crianças a responsabilidade última pelo problema.

As análises evidenciaram, porém, que atribuir as dificuldades de aprendizagem na escola a características orgânicas e cerebrais das crianças tem sido um comportamento bastante usual e validado pelos profissionais da saúde e da educação, num discurso quase uníssono a favor dos psicofármacos. As famílias, por sua vez, não demonstram grande resistência a esse discurso de saber/poder, submetendo-se a ele com uma passividade que pode ter altos custos no futuro de seus filhos e filhas. 
Caminha-se, nesse sentido, para uma interpretação biologizante do problema, desconsiderando-se soluções menos agressivas e mais saudáveis para o cuidado das crianças que, em função de hiperatividade, desatenção ou qualquer outro comportamento tido como inapropriado, apresente resultado insatisfatório na escola. Percebeu-se que 0 uso de drogas medicamentosas na infância, notadamente a Ritalina, tornou-se uma solução mais fácil e aceita. A reflexão sucitada leva a defender outras possibilidades de cuidados às crianças que apresentem comportamentos tidos como fora dos padrões esperados no que tange à aprendizagem escolar e ao comportamento.

Percebeu-se haver um discurso escolar que vem se tornando a cada ano mais imperativo sobre as famílias, notadamente aquelas de menor capital econômicocultural, no sentido de que medicalizem seus filhos e filhas, adequando-as ao modelo esperado de docilidade, calma e passividade. Acusa-se, nesse sentido, uma verdadeira tentativa de robotização da infância. Desconsidera-se, nesse caso, que as crianças são sujeitos que carregam subjetividades particulares e se tenta encaixá-las dentro de um modelo que é, muitas vezes, proposto por uma escola que não sabe e nem mesmo quer aprender a lidar com os desafios que envolvem o processo de ensinar, de aprender a ensinar e de ensinar a aprender.

Sugere-se, nessa oportunidade, a literatura, o cinema, o teatro, a música, a dança, o desenho e a pintura, entre outros suportes artísticos, como elementos potenciamente capazes de promover saúde por meio de um ambiente escolar mais saudável, contribuindo para 0 aprimoramento cultural $e$ fortalecendo as potencialidades intelectivas das crianças. A promoção da saúde deve ser um conceito validado por todos aqueles que de um modo ou de outro encontram-se envolvidos com as crianças em situação de dificuldade e sofrimento.

A revisão permitiu problematizar a perigosa relação entre os interesses da indústria farmacêutica e a medicina, evidenciando que críticas feitas há quase cinco décadas não perderam validade. A análise da medicalizaçao dos portadores de Transtorno de déficit de atenção e hiperatividade exige uma discussão moral que adentre, especialmente, para o campo da bioética e dos direitos humanos das crianças.

A pesquisa evidenciou que embora algumas crianças possam efetivamente apresentar transtornos comprometedores das capacidades cognitivas, o número das que são diagnosticadas com TDAH e, em função disso, medicadas, é preocupante.

Nesta perspectiva, defende que o diagnóstico das crianças com dificuldade de aprendizagem se dê por um viés menos biomédico e mais humanístico, considerando, inclusive, as deficiências e fragilidades do sistema educacional brasileiro.

Nesse aspecto, a dificuldade talvez esteja não na criança que não aprende, mas numa escola que não consegue ensinar. Sugere, para tal fim, que se busquem alternativas menos invasivas do que os psicofármacos como ferramenta de empoderamento cultural e de promoção da saúde infantil.

\section{AGRADECIMENTOS}

Ao Instituto Cesumar de Ciência, Tecnologia e Inovação - ICETI, ao Centro Universitário de Maringá - UNICESUMAR. 


\section{REFERÊNCIAS}

AZEVEDO, L. J. C. Medicalização das infâncias: entre os cuidados e os medicamentos. Psicologia USP, v. 29, n. 3, p. 451-458, 2018. Acesso 31 Jan. 2019. Disponível em <http://dx.doi.org/10.1590/0103-656420180107>. doi:10.1590/0103-656420180107. Acesso em: 13 de outubro de 2018.

BARROCO, S. M. S.; FACCI, M. G. D.; MORAES, R.J.S.de. Posicionamento da Psicologia ante o crescimento da medicalização: considerações educacionais. Medicalização da educação e psicologia histórico-cultural: em defesa da emancipação humana. LEONARDO, N. S. T.; LEAL. Z. F. de R.G.; FRANCO, A. de F. (Orgs). Maringá: EDUEM, 2017, p.17-42.

BOCCATO, T. N. A.; LUCENA, J. E. E.; FRANCO, A. F. Da medicalização ao processo educativo. Medicalização da educação e psicologia histórico-cultural: em defesa da emancipação humana. LEONARDO, N.S.T.; LEAL, Z. F. de R. G. ; FRANCO, A. de F. (Orgs). Maringá: Eduem, 2017, p. 193-214.

BRASIL. Elaboração de Políticas e Estratégias para a Prevenção do Fracasso Escolar. Secretaria de Educação Infantil e Fundamental. Departamento de Políticas Educacionais. Brasília, maio de 2005. Disponível em: $<$ http://www.uniedu.sed.sc.gov.br/index.php/posdefracasso-escolar/file>. Acesso em: 23 de agosto de 2018.

CALIMAN, L. V. Notas sobre a história oficial do transtorno do déficit de atenção/hiperatividade TDAH. Psicologia: ciência e profissão, v. 30 , n. 1, p. 4661, 2010. Disponível em <http://dx.doi.org/10.1590/S1414-98932010000100005>. doi: 10.1590/S1414-98932010000100005. Acesso em: 07 de agosto de 2018.

CARVALHO, S. R.; RODRIGUES, C. O.; COSTA, F. D.; ANDRADE, H. A. Medicalização: uma crítica (im)pertinente? Physis Revista de Saúde Coletiva, v. 25 n. 4, p. 1251-1269, 2015. Disponível em http://www.scielo.br/pdf/physis/v25n4/01037331-physis-25-04-01251.pdf. DOI: 10.1590/S0103-73312015000400011. Acesso em: 22 de outubro de 2018.

CASTRO, C. X. L.; LIMA, R. F. Consequências do transtorno do déficit de atenção e hiperatividade (TDAH) na idade adulta. Revista psicopedagogia, v. 35, n. 106, p. $61-72,2018$

Disponível em http://pepsic.bvsalud.org/scielo.php?script=sci_arttext\&pid=S0103$84862018000100008 \& \mathrm{lng}=$ pt\&nrm=iso. ISSN 0103-8486. Acesso em: 23 de outubro de 2018.

CRUZ, B. S. L. A.; LEMOS, F. C. S.; PIANI, P. P. F. ; BRIGADÃO, J. I. M. Uma crítica à produção do TDAH e a administração de drogas para crianças. Estudos de psicologia, v. 21, n. 3, p. 282-292, 2016. Disponível em <http://www.scielo.br/scielo.php?script=sci_arttext\&pid=S1413294X2016000300282\&lng=en\&nrm=iso>. doi: 10.5935/1678-4669.20160027 Acesso em: 09 de setembro de 2018.

CRUZ, M. G. A; OKAMOTO, M. Y.; FERRAZZA, D. A. Caso Transtorno do Déficit de Atenção e Hiperatividade (TDAH) e a medicalização da educação: uma análise a ENCICLOPÉDIA BIOSFERA, Centro Científico Conhecer - Goiânia, v.16 n.29; p. 1987 2019 
partir do relato de pais e professores. Interface, n. 20, v 58, p. 703-714, 2016. Disponível em <https://www.scielosp.org/article/icse/2016.v20n58/703-714/pt/>. doi: 10.1590/1807-57622015.0575. Acesso em: 23 de agosto de 2018.

DECOTELLI, K. M.; BOHRE, L. C. T.; BICALHO, P. P. G. A droga da obediência: medicalização, infância e biopoder: notas sobre clínica e política. Psicologia: ciência e profissão, v. 33, n. 2, p. 446-459, 2013. Disponível em http://www.scielo.br/scielo.php?script=sci_arttext\&pid=S1414-

98932013000200014\&Ing=en\&nrm=iso>. doi: 10.1590/S1414. Acesso em: 06 de agosto de 2018.

FERNANDES, C. T.; MARCONDES, J. F. TDAH: Transtorno, Causa, Efeito e Circunst TDAH: Transtorno, Causa, Efeito e Circunstância. Revista Ensino, Educação e Ciências Humanas, v. 18, n. 1, p. 48-52, 2017.

FOUCAULT, M. Microfísica do poder. Rio de Janeiro: Record, 2016.

FOUCAULT, M. O Nascimento da Clínica. Rio de Janeiro: Forense Universitária, 2015.

GIUSTA, A. S. Concepções de aprendizagem e práticas pedagógicas. Educação em Revista, v. 29, n. 1, 2013. Disponível em http://www.redalyc.org/articulo.oa?id=282323570012>. doi: 10.1590/S010246982013000100003. Acesso em: 22 de agosto de 2018.

GOTZSCHE, P. C. Medicamentos mortais e crime organizado. Como a indústria farmacêutica corrompeu a assistência médica. Tradução Annyr Porto Fajardo. Porto Alegre, Bookman, 2016.

ILLICH, I. A expropriação da saúde. Nêmesis da medicina. Rio de Janeiro: Nova Fronteira, 1975.

JERUSALINSKY, D. Trata-se de caçar o caçador? In: JERUSALINSKY, A.; FENDRIK, S. O livro negro da psicopatologia contemporânea. São Paulo: Via Lettera, 2011.

KAMERS, M. A falsa epidemia do TDAH e os impasses no uso da metodologia DSM na infância. Estilos da clínica, v. 21, n. 2, p. 516-527, $2016 . \quad$ Disponível em $<$ http://pepsic.bvsalud.org/scielo.php?script=sci_arttext\&pid=S141571282016000200013 >. Acesso em: 21 de julho de 2018.

LARROCA, L. M.; DOMINGOS, N. M. TDAH. Investigação dos critérios do subtipo predominantemente desatento. Revista da Associação Brasileira de Psicologia Escolar e Educacional, v. 16, n. 1, p.113-123, 2012. Disponível em $<$ http://www.scielo.br/scielo.php?script=sci_arttext\&pid=S141385572012000100012>. doi: 10.1590/S1413-85572012000100012 Acesso em: 15 de setembro de 2018. 
LAVAGNINO, N. J.; BARBERO, S.; FOLGUERA, G. Caracterización, alcances y dificultades de las "bases biológicas" del Trastorno por Déficit de Atención e Hiperactividad (TDAH). Un enfoque desde la Filosofía de la Biología. Physis: Revista de Saúde Coletiva, v. 28, n. 1, 2018. Disponível em <https://www.scielosp.org/pdf/physis/2018.v28n1/e280110/es>. doi: 10.1590/S010373312018280110 Acesso em: 04 de julho de 2018.

LEONARDO, N. S. T.; SUZUKI, M. A. Medicalização dos problemas de comportamento na escola: perspectivas de professores. Fractal: Revista de Psicologia, v. 28, n. 1, p. 46-54, 2016. Disponível em <http://www.scielo.br/scielo.php?script=sci_arttext\&pid=S198402922016000100046\&lng=en\&nrm=iso >. doi: 10.1590/1984-0292/1161. Acesso em: 02 de junho de 2018

MACHADO, L. V.; FERREIRA, R. R. A indústria farmacêutica e psicanálise diante da "epidemia da depressão": respostas possíveis. Psicologia em estudo, v. 19, n. 1, p. 135-144, 2014. Disponível em <https://www.redalyc.org/html/2871/287132425015/>. doi: 10.1590/1413-7372219160013. Acesso em: 14 de agosto de 2018.

MICARONI, N. I. R.; CRENITTE, P. A.; CIASCA, S. M. A prática docente frente à desatenção dos alunos no ensino fundamental. Revista CEFAC, v. 12, n. 5, p. 756765, 2010. Disponível em <https://revista.acbsc.org.br/racb/article/viewFile/872/pdf>. Acesso em: 03 de julho de 2018.

MORETTI, V. D. ; ASBHAR, F. S. F.; RIGON, A. J. O humano no homem: os pressupostos teórico-metodológicos da teoria histórico-cultural. Psicologia e Sociedade, $\quad$ v. 23, n. 3, 2011. Disponível em <http://www.scielo.br/pdf/psoc/v23n3/05.pdf>. ISSN 0102-71. Acesso em: 15 de agosto de 2018.

MOYSÉS, M. A. A.; COLLARES, C. A. L. Controle e medicalização da infância. Desidades, v. 1, n. 1, p. 11-21, 2013. Disponível em <https://revistas.ufrj.br/index.php/desidades/article/viewFile/2456/2090>. doi: 10.1590/S1516-18462010005000101. Acesso em: 12 de setembro de 2018.

OLIVEIRA, J.B.A. Repensando a educação brasileira: o que fazer para transformar nossas escolas. São Paulo: Salta, 2015.

PALANGANA, I. C. Desenvolvimento e aprendizagem em Piaget e Vygotski: a relevância do social. São Paulo: Summus Editorial, 2015.

PERRENOUD, P. A pedagogia na escola das diferenças. Fragmentos de uma sociologia do fracasso. Porto Alegre: Artmed, 2001.

RODRIGUES, A.; CHECHIA, V. A. O fracasso escolar e suas implicações no processo de ensino e de aprendizagem. Psicologia: Saberes \& Práticas, v. 1, n. 1, p. 29-36, 2017. Disponível em <http://unifafibe.com.br/revistasonline/arquivos/psicologiasaberes\&praticas/sumario/6 0/11122017213806.pdf>. Acesso em: 03 de junho de 2018. 
ROHDE, L. A.; BARBOSA, G. A.; TRAMONTINA, S.; POLANCZYK, G. Transtorno de déficit de atenção e hiperatividade. Revista Brasileira de Psiquiatria, v. 22, n. 2, p. 7-11, 2000. Disponível em <http://www.scielo.br/scielo.php?script=sci_arttext\&pid=S1516-

$44462000000600003 \& \operatorname{lng}=e n \& n r m=i s o>$. doi: $10.1590 / S 1516-44462000000600003$. Acesso em: 12 de junho de 2018.

ROHDE L. A.; MATTOS, P. Princípios e práticas em Transtorno de Déficit de Atenção/Hiperatividade. Porto Alegre: Artmed, 2003.

SANTOS, L. H. S.; FREITAS, C. R. TDAH, aprimoramento e medicalização no âmbito da Saúde Mental Global: uma entrevista com llina Singh (Parte 2). Interface, v. 22, n. 65, p. 631-641, 2018. Disponível em $<$ www.scielo.br/odf/ucsse/v22n65/1414_3283-icse-22-65-0631.pdf>. doi: 10.1590/1807-57622017.0136. Acesso em: 03 de agosto de 2018.

SANTOS, L. H. S.; FREITAS, C. R. TDAH, educação e cultura: uma entrevista com Ilina Singh (Parte 1). Interface, v. 20, n. 59, p. 1077-1086, 2016. Disponível em $<$ http://www.scielo.br/scielo.php?script=sci_arttext\&pid=S1414-

32832016000401077\&lng=en\&nrm=iso >. doi: 10.1590/1807-57622016.0565. Acesso em: 16 junho de 2018.

SIGNOR, R. C. F.; BERBERIAN, A. P.; SANTANA, A. P. A medicalização da educação: implicações para a constituição do sujeito/aprendiz. Educação e Pesquisa, v. 43, n. 3, p. 743-763, 2017. Disponível em <http://www.journals.usp.br/ep/article/view/136782>. doi: 10.1590/s15179702201610146773 . Acesso em: 16 de setembro de 2018.

SILVA, A. C. P. D.; LUZIO, C. A.; SANTOS, K. Y. P. D.; YASUI, S.; DIONISIO, G. H. A explosão do consumo de ritalina. Revista de Psicologia da UNESP, v. 11, n. 2, p. 44-57, 2012.2 Disponível em <https://repositorio.unesp.br/bitstream/handle/11449/127245/ISSN1984-9044-201211-02-44-57.pdf?sequence=1 >. Acesso em: 05 de setembro de 2018.

SUZUKI, M. A.; LEONARDO, N. S. T.; LEAL, Z. F. de R. G.. A medicalização da educação: reflexões para a compreensão e enfrentamento desse fenômeno. Medicalização da educação e psicologia histórico-cultural: em defesa da emancipação humana. LEONARDO, N. S. T.; LEAL, Z. F.R. G. ; FRANCO, A.F. (Orgs). Maringá: Eduem, 2017, p. 43-70.

TADA, I. N.C.; SILVA, J. M. B. da; GUEDES, L. P. da S.; OLIVEIRA, D. L. S. de; FURTADO, M. C. D.; LOPES, F. R.. Rompendo as mordaças? Contribuições da Psicologia Escolar para o enfrentamento da queixa escolar. Medicalização da educação e psicologia histórico-cultural: em defesa da emancipação humana. LEONẢRDO, N. S. T.; LEAL, Z. F.R. G. ; FRANCO, A.F. (Orgs). Maringá: Eduem, 2017 , p.

109-134.

TOASSA, G. Sociedade Tarja Preta: uma crítica à medicalização de crianças e adolescentes. Fractal: Revista de Psicologia, v. 24, n. 2, p. 429-434, 2012. 
Disponível em <http://www.scielo.br/scielo.php?script=sci_arttext\&pid=S198402922012000200015>. doi: 10.1590/S1984-02922012000200015 Acesso em: 123 de junho de 2018.

WAGNER, F.; ROHDE, L. A; TRENTINI, C. M. Neuropsicologia do Transtorno de Déficit de Atenção/Hiperatividade: Modelos Neuropsicológicos e Resultados de Estudos Empíricos. Psico-USF, v. 21, n. 3, p. 573-582, 2016. Disponível em < http://www.scielo.br/scielo.php?script=sci_arttext\&pid=S1413-

$82712016000300573 \&$ Ing=en\&nrm=iso\&tlng=pt>. $\quad$ doi:

82712016210311. Acesso em: 15 de setembro de 2018.

$10.1590 / 1413-$ 